their existence, or do they merely provide, as Professor Martin Roth has put it, "occupational therapy for university staff" ?

The pursuit of research has, of course, its own merit in creating an atmosphere of intellectual inquiry, and the able physician will be constantly stimulated by the problems posed by the individual patient. But his research must be relevant and it must be directed with the needs of the patient in mind. The beneficial collaboration between physician and surgeon in the accurate investigation and treatment of cardiac disease is a case in point, and advances in other fields are to be expected with the increasing partnership between doctors and technologists. But Platt's chief plea is to break the bonds imposed by measurement (which implies that man is merely a machine) and to repair what he believes to be the greatest failure of clinical science-the almost complete neglect of psychological factors in disease.

From earliest times man has built up elaborate defences against the analysis of his subconscious mind, and this is apparent in the medical schools of today. Patients are interrogated and examined in open outpatients and wards in the presence of numerous students, or are presented as "cases" at grand rounds. Clinical research is directed almost entirely towards organic disease, and until recently the mentally ill, together with psychiatrists, were conveniently segregated in separate institutions. And there are the additional defences that psychological medicine cannot be taught objectively and that the time is not ripe for serious research. Yet no one denies the importance of such factors as heredity, emotional development, social, environmental and cultural influences, chemical changes, and organic cerebral disease in the causation of psychological illness Each of these can be studied by modern techniques, and even the psychiatric interview is amenable to analysis by computer Measurement and controlled experiment may not be possible, but "the unbiased collection and verification of observations" -the central feature of the scientific method-can still be satisfied. Human behaviour is surely a subject worthy of the clinical scientist.

Platt does not expect everyone to accept his views on the shortcomings of academic medicine nor his attempt at a solution. Nevertheless, he is really only reiterating what has been said before in other contexts-that in our effort to teach medicine as a scientific discipline we are in danger of losing those very qualities of understanding, compassion, and a carefully practised technique which are the essence of the good doctor. Science is in danger of becoming the master rather than a servant to be dismissed on the many occasions when the patient is better without its services. Man is presented to medical students today as a corpse or as a machine, and it is natural that their approach to illness should be largely mechanistic. A change in emphasis towards the scientific study of psychological factors in health and disease might well be the bridge to close the gap between the differing qualities of mind that often seem to separate the clinical scientist from the practising physician.

\section{Clomiphene for Ovulation}

The two articles on the artificial induction of ovulation in the B.M.f. this week come at a time when treatment with clomiphene citrate is passing from the research to the clinical stage. Preparations of human pituitary gonadotrophin are at present available for very few patients and under restricted circumstances. They are more dangerous than clomiphene, and their safe use necessitates elaborate facilities for hormone assay. Few would dispute that in the foreseeable future treatment with gonadotrophin preparations should be restricted to a few highly specialized units. Clomiphene, on the other hand, is available on prescription, and its untoward sideeffects are slight. ${ }^{1}$ Thus it is appropriate to consider the indications for prescribing the drug.

The first reports on treatment with clomiphene appeared nearly seven years ago, ${ }^{2}$ and there is now general agreement on the indications for its use, its dosage, its side-effects, and the changes in ovarian hormone production which follow. ${ }^{3-5}$ The means by which its effects are brought about are not clear, so that some caution in prescribing it is wise. It is suitable only for the treatment of infertility associated with anovulation. In disorders of menstruation such as amenorrhoea it seldom brings any prolonged amelioration of the disorder.

In a woman having periods of amenorrhoea for more than three months it may be presumed that ovulation is sufficiently rare to be regarded as absent for clinical purposes. Among the questions that need to be determined before treatment for infertility is begun are whether she has a pituitary capable of producing gonadotrophins, ovaries capable of ovulating, and a uterus able to sustain a pregnancy. Clinical common sense can do much to clarify the diagnosis before elaborate laboratory investigations need to be undertaken. A considerable proportion of patients with primary amenorrhoea have genetic defects such as Turner's syndrome or testicular feminization, or anatomical defects such as congenital absence of the uterus. None of them can be expected to respond to clomiphene. Primary amenorrhoea should therefore be investigated thoroughly before clomiphene therapy is undertaken. Secondary amenorrhoea poses more difficult questions. Some women have signs of low production of ovarian hormone, such as underdeveloped breasts, scanty pubic hair, and a flat vulva. Often this is due to deficient secretion of gonadotrophin by the pituitary. Treatment in this group is apt to be unsuccessful, as Dr. E. Rabau and colleagues show in their paper on page 446 this week. But enough of such women have a pituitary capable of response to make treatment worth trying, particularly if the results of laboratory tests are favourable. If the secondary sex characters are fully developed the outlook is more hopeful, particularly if ovarian enlargement can be detected or some virilization is evident. ${ }^{\circ}$

Infertility associated with secondary amenorrhoea can often be successfully treated with clomiphene. In carefully selected patients the success rate approaches $50 \%$, but this can be achieved only after exacting preliminary laboratory investigation. Probably the most useful single test in selecting those amenorrhoeic patients who are suitable for clomiphene is an

\footnotetext{
1 Lamb, E. J., and Guderian, A. M., Obstet. and Gynec., 1966, 28, 505. Greenblatt, R. B., Barfield, W. E., Jungck, E. C., and Ray, A. W., 3. Amer. med. Ass., 1961, 178, 101.

s Bell, E. T., Loraine, J. A., Harkness, R. A., and Foss, G. L., f. Obster. Gynaec. Brit. Cwlth, 1966, 73, 766.

- Whitelaw, M. J., Fertil. and Steril., 1966, 17, 584

s Brit. med. F., 1966, 1, 1436.

Kistner, R. W., Obstet. gynec. Surv., 1965, 20, 873.
} 
assay of the urinary excretion of oestrone. Women who excrete more than $5 \mu \mathrm{g}$. of oestrone per 24 hours have evidence of some residual ovarian activity and are likely to respond to the drug. A nonspecific method for assaying oestrogen, such as that successfully employed by Dr. D. Ferriman and his colleagues (page 444), gives some indication of ovarian response, but its sensitivity in distinguishing between those patients who are likely to respond to clomiphene and those who are not may be questioned. They found that patients with menstrual cycles of less than six months were more likely to respond successfully to clomiphene than those with longer cycles.

Women whose endogenous ovarian activity is sufficient for them to have fairly regular menstruation but who do not ovulate are the most rewarding group for clomiphene therapy, but they are also the most difficult to identify with any assurance. Endometrial biopsy and assay of urinary pregnanediol are more reliable means of detecting ovulation than basal temperature charts. Even for a nulliparous woman an endometrial biopsy should not entail more than a few hours in hospital and does not require an anaesthetic. The assay of urinary steroids like pregnanediol and oestrone is a different matter. These procedures have been out of the research stage for more than a decade, but few teaching hospitals have initiated specific techniques for carrying them out, most clinical centres lack facilities for doing them, and some use simplifications which are inadequate for clomiphene therapy.

There is little point in starting clomiphene therapy unless it can be established that the woman does not ovulate, is capable of ovulation, and has a fertile husband. To this end gonadotrophin assays are helpful, but they are available to few patients. Oestrogen and pregnanediol assays are wellnigh essential, and a semen analysis is mandatory. To determine whether a woman responded at all to clomiphene and when she ovulated requires nearly continuous 24 -hour collections of urine for steroid assays over two to three weeks. This can be done on an outpatient basis; the diagnosis and therapy can be undertaken only with the aid of a specialist clinic. Without the collaboration of such services the use of clomiphene in general practice is clearly unwise. It is a fine example of a situation where the skilful use of laboratory resources can be of great benefit to a few people while a failure to use them can do harm to a larger number.

\section{Blue Blood}

In these days of egalitarianism blue blood is no longer the much sought after prerequisite of the nobility ; indeed, it has of late become fashionable to disclaim such an inheritance. Nature unfortunately cannot be so denied; we are all the inheritors of blue blood, or almost all. Those of us who are aot so endowed are certainly severely underprivileged nembers of the community, though it will take more than an Act of Parliament to put things right. Normal plasma contains a blue copper protein, caeruloplasmin, first isolated by C. G. Holmberg and C. B. Laurell ${ }^{2}$ in 1947 and 1948 and so named because of its colour. In $1952 \mathrm{I}$. H. Scheinberg and D. Gitlin ${ }^{3}$ showed that in patients with Wilson's disease this protein was markedly deficient or even entirely absent from the plasma, and they suggested that this was the primary metabolic defect in the disease.
The Scheinberg hypothesis was entirely reasonable; failure to elaborate this normal plasma protein resulted in the plasma copper remaining diffusable so that it entered the tissues in abnormal amounts. This led to basal ganglia degeneration in the brain and consequently to the bizarre sequence of motor disturbances which are so characteristic of the disease. In the liver excess copper led to necrosis and fibrosis, in the kidneys to defects of tubular reabsorption, and in the eyes to the typical Kayser-Fleischer pigment rings which are diagnostic of the disease. Unfortunately, as G. E. Cartwright and his associates ${ }^{4}$ have pointed out, in their experiencewhich mirrors that of most workers in this field-there is a poor correlation between caeruloplasmin concentration and the duration and severity of the clinical course of the illness. In fact, patients are occasionally seen with perfectly normal levels of this protein in their blood, as was early reported by A. G. Bearn and H. G. Kunkel ${ }^{5}$ and also by Cartwright's group. ${ }^{6}$

One possible explanation of this discrepancy, and a very attractive one at that, was the hypothesis that the caeruloplasmin present in some patients with Wilson's disease was structurally and therefore functionally abnormal. Thus there might be two different alleles mediating the disease, one leading to failure of protein synthesis and one to abnormalities of protein structure, either of which could give rise to the same disastrous functional derangement in the transport of copper in the body. This theory was discussed by a number of delegates at the London meeting on Wilson's disease held at the National Hospital in $1960,{ }^{7}$ but we have had to wait for seven years before further light has been thrown on this aspect of the problem. Now N. A. Holtzman and his colleagues $^{8}$ working at the Johns Hopkins Hospital in Baltimore have isolated and crystallized caeruloplasmin from a patient with Wilson's disease in whom the concentration of this protein in the blood approached normal levels. Their findings of a normal tryptic peptide map go a long way to disproving the theory of a structurally abnormal caeruloplasmin in Wilson's disease. These workers note, as others have done, that when treatment with penicillamine is instituted caeruloplasmin disappears from the plasma, and they postulate the occurrence of a reduced rate of synthesis of caeruloplasmin in their patient ; when the excess copper stores were removed by penicillamine the stimulus to further synthesis of the protein became inadequate. This may well be true, but unfortunately it takes us no further in our understanding of the disease. Indeed, one of the main stumblingblocks to our understanding of the pathogenesis of this mysterious illness is the complete absence of clues to the normal function of caeruloplasmin. ${ }^{9}$ L. Broman ${ }^{10}$ has even described it as " just an ineffective oxidase, in the wrong place, lacking a suitable substrate," but he himself believes that it represents a transport form of a copper-containing prosthetic

1 Holmberg, C. G., and Laurell, C. B., Acta chem. scand., 1947, 1, 944. ibid., 1948, 2, 550 .

- Scheinberg, I. H., and Gitlin, $D_{.,}$Science, 1952, 116, 484. Wintrobe M. M., Amer. F.' Med., 1960, 28,'555.

- Bearn, A. G., and Kunkel, H. G., F. clin. Invest., 1954, 33, 400.

- Markowitz, H., Gubler, C. J., Mahoney, J. P., Cartwright, G. E., and Wintrobe, M. M., ibid., 1955, 34, 1498.

' Wilson's Disease : Some Current Concepts, ed. J. M. Walshe and J. N. Cumings, Oxford, 1961.

8 Holtzman, N. A., Naughton, M. A., Iber, F. L., and Gaumnitz, B. M. 7. clin. Invest., 1967, 46, 993.

- Holmberg, C. G., in Wilson's Disease : Some Current Concepts, ed. J. M. Walshe and J. N. Cumings, Oxford, 1961, p. 64.

10 Broman, L., Acta Soc. Med. upsalien, 1964, 69, suppl. No. 7.

10 Broman, L., Acta Soc. Med. upsalien, 1964, 69, suppl. No.

11 Aisen, P.. Morell, A. G., Alpert, S., and Sternlieb, I., Nature, 1964, 203, 873 . 